\title{
Special Nanoskin-ACT-Biological Membranes from Deep Wounds
}

\author{
Saqer Al Mualla1, Mashael Al Nabooda', Noura Salim Salman', Pierre Basmaji², \\ Gabriel Molina De Olyveira ${ }^{3 *}$, Ligia Maria Manzine Costa4, \\ José Domingos Da Costa Oliveira², Gino Bruno Francozo² \\ ${ }^{1}$ Al Qassimi Hospital/Kuwait Hospital, Sharjah, United Arab Emirates \\ ${ }^{2}$ Biotechnology Research and Development, São Carlos, Brazil \\ ${ }^{3}$ Department of Nanomedicine and Nanotoxicology, IFSC-USP, São Carlos, Brazil \\ ${ }^{4}$ Materials Engineering Department, São Carlos School of Engineering, University of São Paulo, São Paulo, Brazil \\ Email: *gabriel.ufabc@gmail.com, *gmolyveira@yahoo.com.br
}

How to cite this paper: $\mathrm{Al}$ Mualla, S., $\mathrm{Al}$ Nabooda, M., Salman, N.S., Basmaji, P., De Olyveira, G.M., Costa, L.M.M., Da Costa Oliveira, J.D. and Francozo, G.B. (2018) Special Nanoskin-ACT-Biological Membranes from Deep Wounds. Journal of Biomaterials and Nanobiotechnology, 9, 79-88. https://doi.org/10.4236/jbnb.2018.91007

Received: December 12, 2017

Accepted: January 15, 2018

Published: January 18, 2018

Copyright $\odot 2018$ by authors and Scientific Research Publishing Inc. This work is licensed under the Creative Commons Attribution International License (CC BY 4.0).

http://creativecommons.org/licenses/by/4.0/

\begin{abstract}
Bacterial cellulose (BC) is established as a newest biomaterial, and it can be used for medical and odontology applications. In addition, it has called attention for uses such as membrane for wound care and tissue engineering. In this work, the bacterial cellulose fermentation process is modified by the addition of natural materials before the bacteria are inoculated. In vivo behavior using natural ECM for regenerative medicine is presented and completed wound healing process is 3 months.
\end{abstract}

\section{Keywords}

Bacterial Cellulose (Nanoskin ${ }^{\circledR}$ ) \& ACT (Advanced Cell Therapy), Natural Nanocomposites, Tissue Engineering

\section{Introduction}

Patients with chronic wounds are treated successfully (80\%) by the district nurse or practice nurse staff [1].

After a certain time, often self-determined by the community nurse team, the non-healing patient is referred to a "wound care specialist" who will initially assess the wound care policy and patient records of how they have been treated to date. If the treatment was deemed to be poor or sub optimal, the wound care specialist will initially instigate a "gold standard" regime of advanced wound care therapy. If this therapy is successful they will continue to heal with advanced wound care alone [2]. 
If the previous treatment undertaken was deemed to be good or gold standard care, the wound care specialist will assess the wound and recommend/use a series of advanced therapies which would be needed to promote the ultimate healing of the wound [3].

The improved understanding of the physiology of wounds and the processes involved in wound healing have resulted in a change of understanding as regards the wound environment and healing [3].

Previous non-healing wounds were assumed to have a deficiency in the epithelial cells, it is excepted a problem of Extra Cellular Matrix (ECM) which is the major issue in static non healing chronic wounds [4].

In this scope, Natural ECM is the ideal biological scaffold since it contains all the components of the tissue. Constructive remodeling can be performed using such natural ECM scaffolds and vegetal/animal stem cells since, the cells can be delivered to the site of infraction and once delivered the cells help wound dressing process. The development of niche mimicking biomaterials and hybrid biomaterial can further advance directed differentiation without specific induction [5] [6].

The extracellular matrix (ECM) contains an abundant variety of signals that are received by cell surface receptors and contribute to cell adhesion and cell fate, via regulation of cellular activities such as proliferation, migration and differentiation. As such, regenerative medicine studies often rely on mimicking the natural ECM to promote the formation of new tissue by host cells, and characterization of natural ECM components is vital for the development of new biomimetic approaches [7] [8].

Bacterial cellulose (BC)-Nanoskin ${ }^{\circledR}$ \& ACT (Advanced Cell Therapy) is a natural cellulose produced by bacterial synthesis by biochemical steps and self-assembling of the secreted cellulose fibrils on the medium. Shaping of BC materials in the culture medium can be controlled by the type of cultivation that changes chain size, origin of strains which produces different proportions of crystalline phase of $\mathrm{BC}$ and the kind of bioreactor. $\mathrm{BC}$ hydrogel or BC in dry state is then obtained by methods, such as freeze-drying [9] [10]. The structural features of microbial cellulose, its properties and compatibility as a biomaterial for regenerative medicine can be changed by modifying its culture medium [11] or surface modification by physical [12] [13]; chemical methods [14] and genetic modifications [15] to obtain a biomaterial with less rejection when in contact to the body [16] [17].

Bacterial cellulose fibers mimics Collagen in creating an extra cellular matrix in the wound, which is neither originating from Animals (e.g. SIS matrix) nor synthetic (man-made), and it therefore must be described as Artificial Biology. This artificial biological ECM replaces the body's own lost or damaged ECM and also stimulates the body to produce more of its own Collagen, which supports the body's wound healing closure mechanism. Stimulating Fibroblast production and subsequently TGF $-\beta$ (Transforming growth factor beta) production will 
also be stimulated. Then granulation and epithelialization will start due to the presence of fibroblasts, endothelial cells are attracted to the wound producing growth factors, fibroblasts will release the body's own collagen and glycosaminoglycans. The combination of collagen and fibronectin forms the new ECM, ECM synthesis and new vessels, granulation tissue formation and epithelialization by Keratinocyte migration, results in and increase in the dermis volume and accelerating the healing [18] [19].

However, structural changes may interfere with the physical chemical properties of the surface, producing a biomaterial with properties like tissue/implant interface stability suitable for cell adhesion. Besides, recent works study chemical changes in bacterial cellulose surface for tissue engineering and regenerative medicine [20] [21] [22].

In this work, novel in vivo studies of natural nanocomposites with bacterial cellulose for functional materials are reported with complete wound healing. In order to produce scaffolds with drug delivery ability and better cell adhesion, fermentation changes in bacterial cellulose with chondroitin sulfate, hyaluronic acid and beta glucan were performed and its in vivo cell behavior is presented.

\section{Materials and Methods}

\subsection{Materials}

The bacterial cellulose-Nanoskin ${ }^{\circledR} \&$ ACT (Advanced Cell Therapy) raw material was provided from Innovatec's (São Carlos SP, Brazil). Chondroitin sulfate, hyaluronic acid sodium salt from Streptococcus equi (bacterial glycosaminoglycan polysaccharide) and beta glucan were purchased from Sigma Aldrich.

\subsection{Methods}

\subsubsection{Synthesis of Bacterial Cellulose and Bacterial Cellulose/ Chondroitin Sulfate/Hyaluronic Acid/Beta-Glucan}

The acetic fermentation process was achieved by using glucose as a carbohydrate source. Results of this process are vinegar and a nanobiocellulose biomass. The modifying process is based on the addition of hyaluronic acid, chondroitin sulfate and beta-glucan $(1 \% \mathrm{w} / \mathrm{w})$ to the culture medium before the bacteria is inoculated. Bacterial cellulose (BC) is produced by Gram-negative bacteria Gluconacetobacter xylinus, which can be obtained from the culture medium in the pure 3-D structure, consisting of an ultra fine network of cellulose nanofibers [19].

\subsubsection{Bionanocomposite Preparation}

In the present study, a novel biomaterial has been explored and bacterial cellulose nanocomposites have been prepared; $\mathrm{BC} /$ chondroitin sulfate, hyaluronic acid and beta glucan $(\mathrm{BC} 1)$.

\subsection{Characterization}

Transmission infrared spectroscopy (FTIR, Perkin Elmer Spectrum 1000). 
Influences of hyaluronic acid, chondroitin sulfate and beta-glucan in bacterial cellulose were analyzed in the range between 250 and $4000 \mathrm{~cm}^{-1}$ and with $2 \mathrm{~cm}^{-1}$ resolution with samples.

In vivo analysis evaluation-Clinical study at Sharjah kuwait hospital under supervision of Dr. Saqer Al Mualla Consultant Head of Plastic Surgeons Department, Dr. Mashael Al Nabooda Plastic Surgeon Specialist and Dr. Noura Salim Salman plastic surgeon specialist in evaluation case-patient knocked by car presented with deep laceration of the lateral aspect of the right leg and foot, with loss of skin, soft tissue over the right and lateral malleolus. The wounds show necrotic tissue with black parts, bad offensive odor and small amount of pus.

\section{Results and Discussion}

\subsection{FTIR-Interaction between Bacterial Cellulose with Materials}

Influences of hyaluronic acid (HA), chondroitin sulfate (CS) and beta glucan in bacterial cellulose were analyzed in the range between 250 and $4000 \mathrm{~cm}^{-1}$ and with resolution of $2 \mathrm{~cm}^{-1}$ with FTIR analysis. The main features of the bacterial cellulose in infrared spectroscopy is: $3500 \mathrm{~cm}^{-1}: \mathrm{OH}$ stretching, $2900 \mathrm{~cm}^{-1}: \mathrm{CH}$ stretching of alkane and asymmetric $\mathrm{CH}_{2}$ stretching, $2700 \mathrm{~cm}^{-1}: \mathrm{CH}_{2}$ symmetric stretching, $1640 \mathrm{~cm}^{-1}$ : OH deformation, $1400 \mathrm{~cm}^{-1}: \mathrm{CH}_{2}$ deformation, $1370 \mathrm{~cm}^{-1}$ : $\mathrm{CH}_{3}$ deformation, $1340 \mathrm{~cm}^{-1}$ : OH deformation and $1320-1030 \mathrm{~cm}^{-1}$ : $\mathrm{CO}$ deformation [23].

It can be observed similar $\mathrm{OH}$ stretching (at $2900 \mathrm{~cm}^{-1}$ ) in bacterial cellulose/ beta glucan composites, however with hyaluronic acid (BC/HA) and chondroitin sulfate (BC/CS) addition, there is differences mainly because of the $\mathrm{NH}_{2}$ interaction with hydroxyl groups (Figure 1). Besides, similar transmission peaks can be observed in the symmetrical stretching of $\mathrm{CH}_{2}$ bonds of bacterial cellulose structures at peak of $1640 \mathrm{~cm}^{-1}$ and similar transmission peak was obtained in the range of $1490 \mathrm{~cm}^{-1}$ on both samples, which shows the presence of a carbonyl

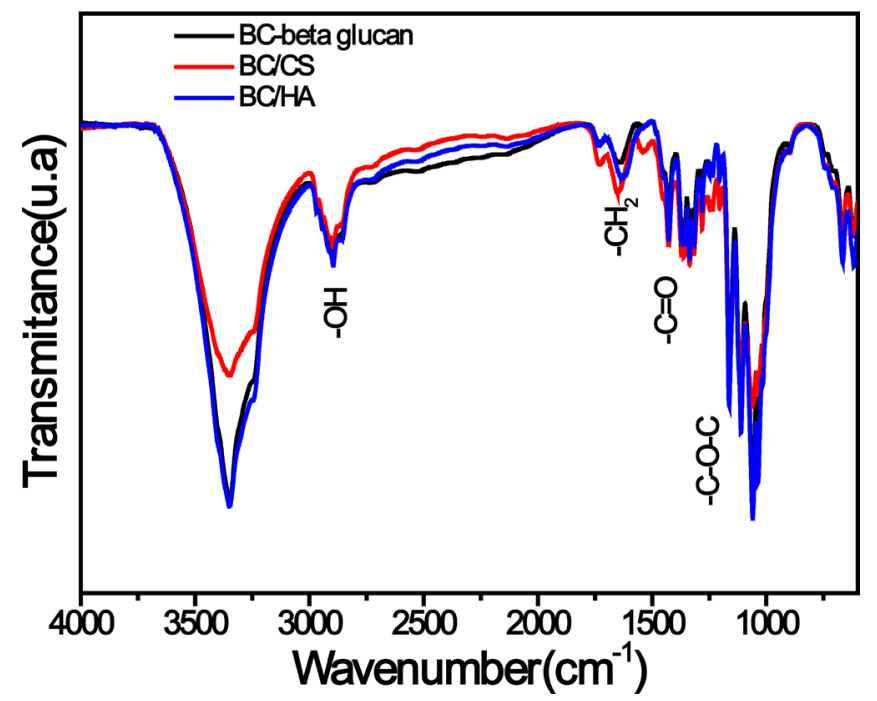

Figure 1. FTIR spectra of bacterial cellulose nanocomposites. 
group in the bacterial cellulose together with bonds corresponding to those of glycoside, including C-O-C at $1162 \mathrm{~cm}^{-1}$ [24], which clearly show one strong hydrogen bond between bacterial cellulose-beta glucan and chondroitin sulfate/hyaluronic acid, mainly by hydroxyl and carbonyl groups.

\subsection{In Vivo Analysis}

Child Patient (M.M) enters in Al Qassimi Hospital/Kuwait Hospital on April 2017, diagnosed with Amputation prognosis. It was performed immediate intervention with clinical protocols for this disease using doctors procedures for cleaning the wound.

In April 2017 there is some Minimal debridement by Debrisoft as observed in Figure 2.

In April $15^{\text {th }}-2017$ started treatment with Bacterial cellulose-ACT (Nanoskin ${ }^{\circledR}$ ) membranes. After using the Bacterial cellulose material in alternate days, it can be observed an excellent recovery of the edge and bottom of the wound and wound area reduction. The aesthetic gain of the lesion was excellent as observed in Figure 3 and Figure 4.

Leg wound on NanoSkin ${ }^{\circledR}$ was kept for 1 week and foot wound was change in alternate day dressing with NanoSkin ${ }^{\circledR}$-ACT. The simple application of dressing, only required the association of saline, gauze and bandage, decrease patient stay and operating room use, resulting in a better cost- benefit as observed in Figure 4. Besides, it can be observed leg wound healed well and foot wound covered by healthy Granulation tissue which started to cover the exposed bone as observed in Figure 4(b). In Figure 4(c), child was discharged and foot wound shows no more exposed bone shifter to NanoSkin dressing weekly.

Finally, laser $\mathrm{CO}_{2}$ and Nanoskin ${ }^{\circledR}$-ACT membranes complete wound healing process only in two and three months as observed in Figure 5(a) and Figure $5(b)$.

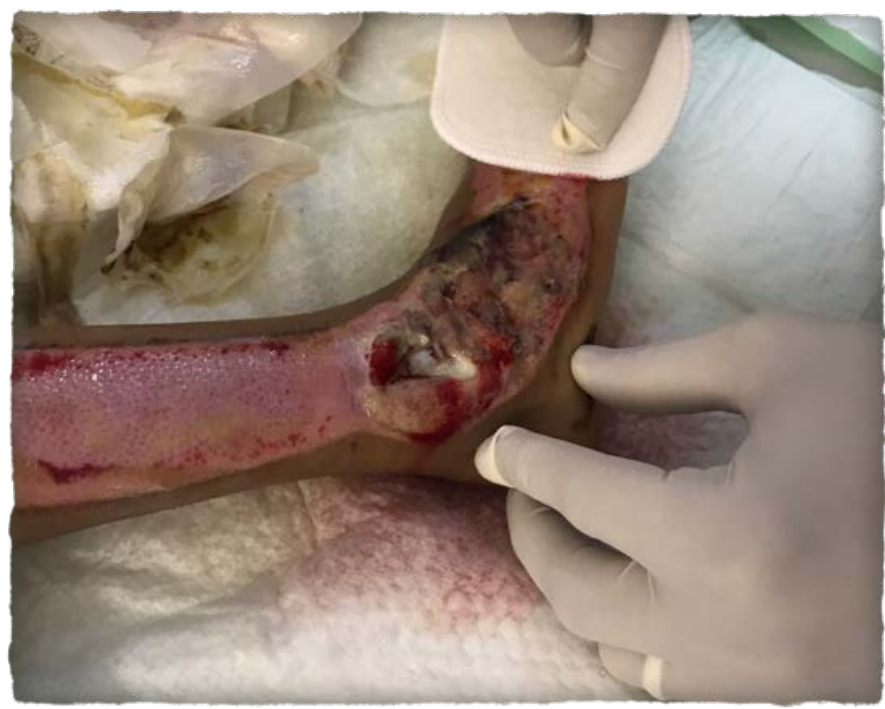

Figure 2. Wound healing with minimal debridement. 


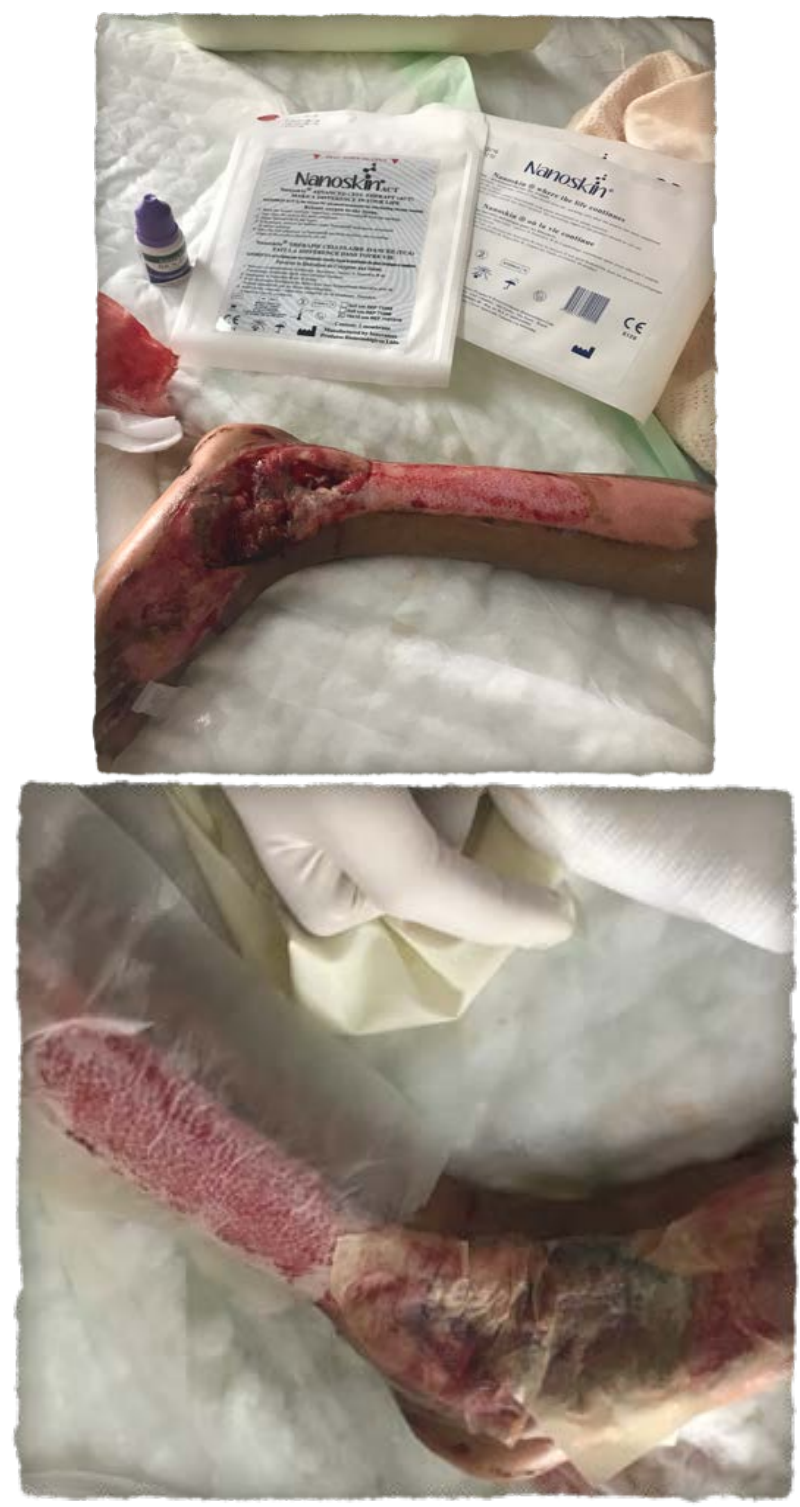

Figure 3. Wound healing with bacterial cellulose-ACT-Nanoskin ${ }^{\circledR}$ membranes.

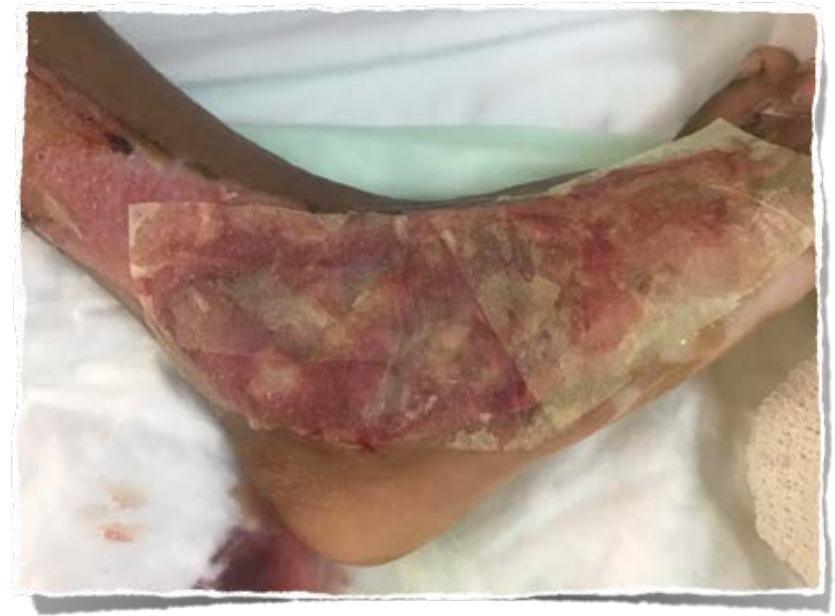

(a) 


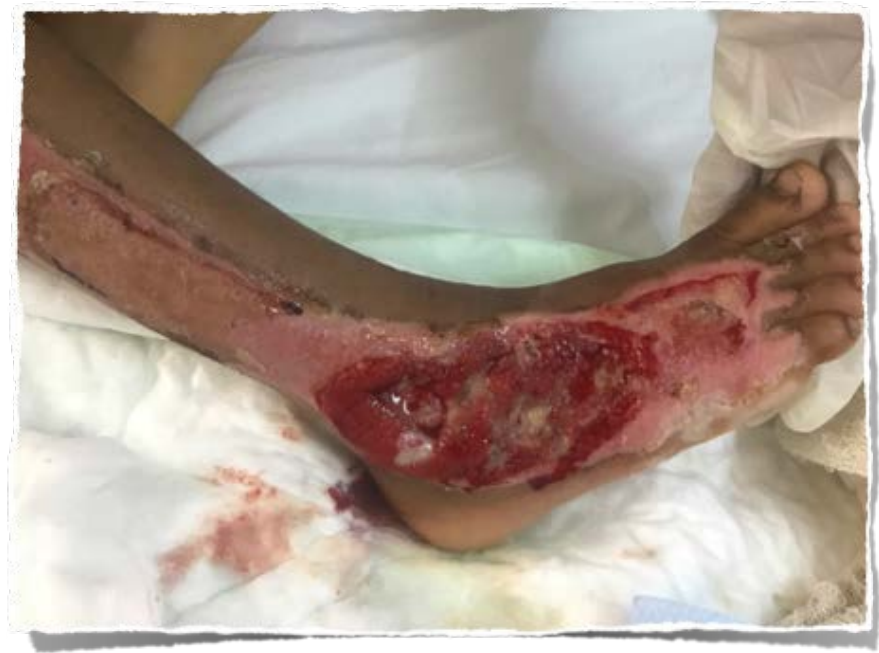

(b)

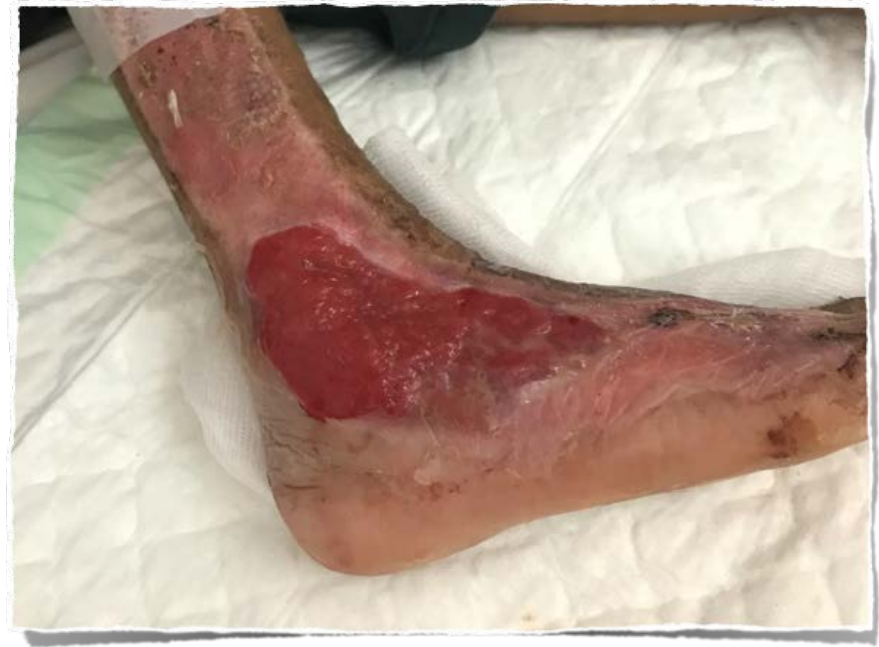

(c)

Figure 4. Wound healing with bacterial cellulose-ACT-Nanoskin ${ }^{\circledR}$ membranes after 1 week ((a) and (b)) and 1 month (c).

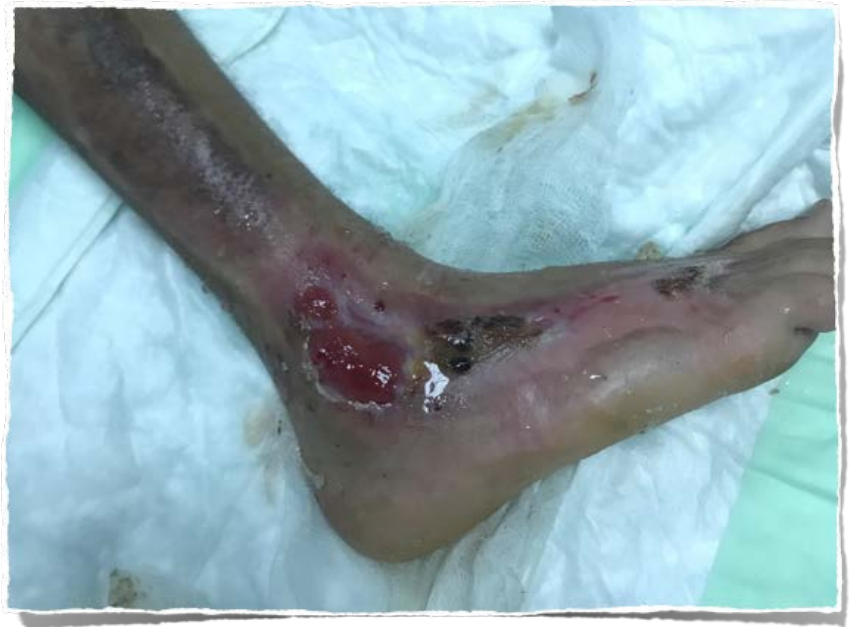

(a) 


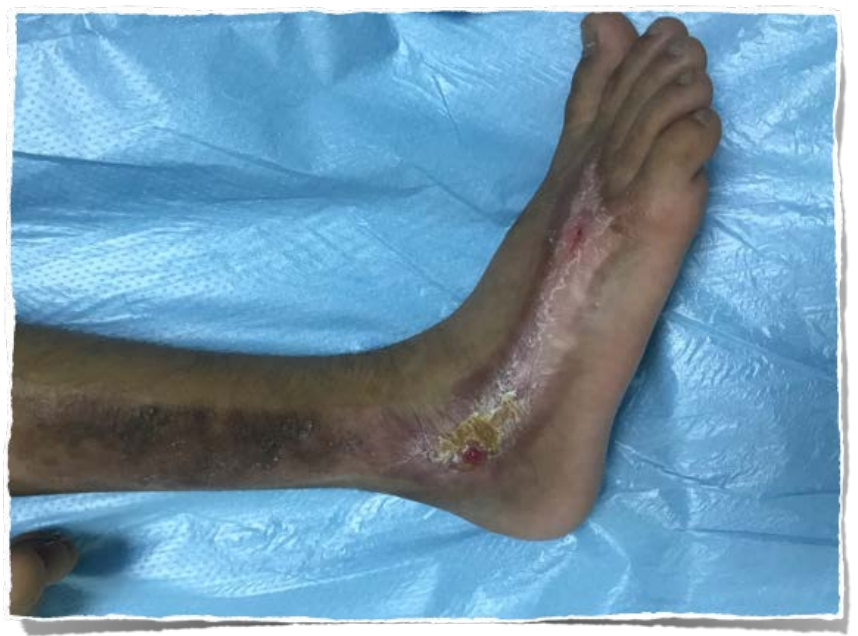

(b)

Figure 5. Final Wound healing process with bacterial cellulose-ACT-Nanoskin ${ }^{\circledR}$ membranes after 2 months (a) and 3 months (b).

\section{Conclusions}

Bacterial cellulose (Nanoskin ${ }^{\circledR}$ ) was successfully modified by changing the fermentation medium with natural materials as shown by FTIR, which produced suitable scaffolds for use in applications like cell attachment, drug delivery and wound healing process. A natural scaffold produced with bacterial cellulose has good tissue adhesion over time and compatibility, being an extremely effective material for tissue regeneration. Thus, undoubtedly, natural-origin polymers or nature-inspired materials appear as the natural and desired choice for medical and dental applications.

In conclusion, Natural bacterial cellulose membranes are applied to protective cover and sutures, with or without exudate lesions and different burn area, changing burn to favorable wound healing, besides, process takes few months and can be used for all age people.

\section{References}

[1] Canavan, R., Connolly, V., Mcintosh, J., Airey, M. and Unwin, N. (2003) Geographic Variation in Lower Extremity Amputation Rates. Diabetic Foot, 6, 82-89.

[2] Vowden, K.R. and Vowden, P. (1996) Peripheral Arterial Disease. Journal of Wound Care, 5, 23-26. https://doi.org/10.12968/jowc.1996.5.1.23

[3] Van Gent, W.B., Wilschut, E.D. and Wittens, C. (2010) Management of Venous Ulcer Disease. BMJ, 341, c6045. https://doi.org/10.1136/bmj.c6045

[4] Rayner, R., Carville, K., Keaton, J., Prentice, J. and Santamaria, X.N. (2009) Leg Ulcers: Atypical Presentations and Associated Comorbidities. Wound Practice and Research, 17, 168-185.

[5] Rahman, G.A., Adigun, I.A. and Fadeyi, A. (2010) Epidemiology, Etiology, and Treatment of Chronic Leg Ulcer: Experience with Sixty Patients. Annals of African Medicine, 9, 1-4. https://doi.org/10.4103/1596-3519.62615

[6] Faria, E., Blanes, L., Hochman, B., Filho, M.M. and Ferreira, L. (2011) Health-Related 
Quality of Life, Self-Esteem, and Functional Status of Patients with Leg Ulcers. Wounds, 23, 4-10.

[7] Siddiqui, A.R. and Bernstein, J.M. (2010) Chronic Wound Infection: Facts and Controversies. Clinics in Dermatology, 28, 519-526.

https://doi.org/10.1016/j.clindermatol.2010.03.009

[8] Han, A., Zenilman, J.M., Melendez, J.H., Shirtliff, M.E., Agostinho, A., James, G., Stewart, P.S., Mongodin, E.F., Rao, D., Rickard, A.H. and Lazarus, G.S. (2011) The Importance of a Multi-Faceted Approach to Characterizing the Microbial Flora of Chronic Wounds. Wound Repair and Regeneration, 19, 532-541.

https://doi.org/10.1111/j.1524-475X.2011.00720.x

[9] Olyveira, G.M., Costa, L.M.M., Riccardi, C.S., Santos, M.L., Daltro, P.B., Basmaji, P., Daltro, G.C. and Guastaldi, A.C. (2016) Bacterial Cellulose for Advanced Medical Materials. In: Grumezescu, A.M., Ed., Nanobiomaterials in Soft Tissue Engineering, Elsevier, Romania, 57-82. https://doi.org/10.1016/B978-0-323-42865-1.00003-9

[10] Olyveira, G.M., Santos, M.L., Riccardi, C.S., Costa, L.M.M., Daltro, P.B., Basmaji, P., Daltro, G.C. and Guastaldi, A.C. (2015) Bacterial Cellulose Biocomposites for Periodontology Treatment. Advanced Science, Engineering and Medicine, 7, 409-414. https://doi.org/10.1166/asem.2015.1641

[11] Costa, L.M.M., Olyveira, G.M., Basmaji, P. and Filho, L.X. (2011) Bacterial Cellulose Towards Functional Green Composites Materials. Journal of Bionanoscience, 5, 167-172. https://doi.org/10.1166/jbns.2011.1060

[12] Costa, L.M.M., Olyveira, G.M., Basmaji, P. and Filho, L.X. (2012) Bacterial Cellulose towards Functional Medical Materials. Journal of Biomaterials and Tissue Engineering, 2, 185-196. https://doi.org/10.1166/jbt.2012.1044

[13] Olyveira, G.M., Costa, L.M.M. and Basmaji, P. (2013) Physically Modified Bacterial Cellulose as Alternative Routes for Transdermal Drug Delivery. Journal of Biomaterials and Tissue Engineering, 3, 227-232. https://doi.org/10.1166/jbt.2013.1079

[14] Olyveira, G.M., Riccardi, C.S., Santos, M.L., Costa, L.M.M., Daltro, P.B., Basmaji, P., Daltro, G.C. and Guastaldi, A.C. (2014) Bacterial Cellulose Nanobiocomposites for Periodontal Disease. Journal of Bionanoscience, 8, 319-324. https://doi.org/10.1166/jbns.2014.1241

[15] Basmaji, P., Olyveira, G.M. and Costa, L.M.M. (2015) Nanoskin Extracellular Matrix Modified with Hyaluronic Acid and Chondroitin Sulfate for Regenerative Medicine Applications. Journal of Bionanoscience, 9, 306-310. https://doi.org/10.1166/jbns.2015.1304

[16] Filho, L.X., OLyveira, G.M., Costa, L.M.M. and Basmaji, P. (2013) Novel Electrospun nanotholits/PHB Scaffolds for Bone Tissue Regeneration. Journal of Nanoscience and Nanotechnology, 13, 4715-4719. https://doi.org/10.1166/jnn.2013.7191

[17] Basmaji, P., Ambrizzi, D.R., Olyveira, G.M., Costa, L.M.M., Francozo, G.B. and Oliveira, J.D.C. (2016) Natural Extracellular Matrix Modified for Tissue Engineering Applications. Advanced Science, Engineering and Medicine, 8, 62-67.

[18] Olyveira, G.M., Santos, M.L., Daltro, P.B., Basmaji, P., Daltro, G.C. and Guastaldi, A.C. (2014) Bacterial Cellulose/Chondroitin Sulfate for Dental Materials Scaffolds. Journal of Biomaterials and Tissue Engineering, 4, 150-154. https://doi.org/10.1166/jbt.2014.1155

[19] Olyveira, G.M., Santos, M.L., Costa, L.M.M., Daltro, P.B., Basmaji, P., Daltro, G.C. and Guastaldi, A.C. (2014) Bacterial Cellulose Nanobiocomposites for Dental Materials Scaffolds. Journal of Biomaterials and Tissue Engineering, 4, 536-542. 
https://doi.org/10.1166/jbt.2014.1202

[20] Olyveira, G.M., Santos, M.L., Costa, L.M.M., Daltro, P.B., Basmaji, P., Daltro, G.C. and Guastaldi, A.C. (2014) Bacterial Biocomposites for Guided Tissue Regeneration. Science of Advanced Materials, 6, 2673-2678.

https://doi.org/10.1166/sam.2014.1985

[21] Olyveira, G.M., Santos, M.L., Costa, L.M.M., Daltro, P.B., Basmaji, P., Daltro, G.C. and Guastaldi, A.C. (2015) Physically Modified Bacterial Cellulose Biocomposites for Guided Tissue Regeneration. Science of Advanced Materials, 7, 1657-1664. https://doi.org/10.1166/sam.2015.2283

[22] Olyveira, G.M., Basmaji, P., Costa, L.M.M., Santos, M.L., Riccardi, C.S., Guastaldi, F.P.S., Scarel-Caminaga, R.M., Oliveira Capote, T.S., Pizoni, E. and Guastaldi, A.C. (2017) Surface Physical Chemistry Properties in Coated Bacterial Cellulose Membranes with Calcium Phosphate. Materials Science \& Engineering. C, Materials for Biological Applications, 75, 1359-1365.

https://doi.org/10.1016/j.msec.2017.03.025

[23] Olyveira, G.M., Chanfrau, J.E.R., Costa, L.M.M., Basmaji, P., Ambrozini, B., Pizoni, E. and Guastaldi, A.C. (2017) Physical Chemistry Properties Influences in Bacterial Cellulose Biocomposites. Journal of Bionanoscience, 11, 573-577.

https://doi.org/10.1166/jbns.2017.1477

[24] Kondo, T. (2005) Hydrogen Bonds in Cellulose and Cellulose Derivatives. In: Dumitriu, S., Ed., Polysaccharides. Structural Diversity and Functional Versatility, Marcel Dekker, Inc., New York, 69-99. 